\title{
Psychological factors in gastro-oesophageal reflux disease
}

'The good doctor ... is also a man who studies the patient's personality as well as his disease.' Sir Hugh Cairns ${ }^{1}$

More than one hundred years ago, Sir William Osler noted that 'oesophagismus is met with in hysterical patients and hypochondriacs ... the idiopathic form is found in females of a marked neurotic habit'. ${ }^{2}$ Since then the role of psychological factors in many oesophageal disorders has been well documented. These include the nutcracker oesophagus which causes chest pain and upper oesophageal sphincter abnormalities that may manifest as globus. However, unlike gastro-oesophageal reflux disease (GORD), these disorders are not among the most common oesophageal disorders.

Until recently GORD has been regarded almost universally as an entirely physical disorder caused by the excessive presence of acid and gastric refluxate in the oesophagus. Several anatomical and pathological factors have been implicated in the pathophysiology of GORD, with good evidence to support the role played by a hiatus hernia, a weak or inappropriately relaxing lower oesophageal sphincter, and inefficient oesophageal clearance. These physical factors by themselves, however, are an inadequate explanation for GORD - they neither account for all the symptoms nor predict adequately the degree of oesophageal acid exposure.

When an attempt is made to correlate physical findings with patient symptomatology, only one quarter of patients with reflux symptoms have grade II or greater oesophagitis, $27 \%$ have lower oesophageal sphincter pressures within the normal range, and over one quarter have normal oesophageal acid exposure times. ${ }^{3-5}$ By contrast, $20-30 \%$ of patients with Barrett's oesophagus or oesophageal strictures give no history of symptoms. ${ }^{67}$ Further confirmation of this discrepancy was documented by Smith et al who noted that individuals were sensitive to liquids of differing hydrogen ion concentration - some perceived heartburn at $\mathrm{pH} 6$, others were insensitive to $\mathrm{pH} 2 .{ }^{8}$ The ability of physical and demographic details to predict the degree of oesophageal acid exposure measured by $\mathrm{pH}$ monitoring has been examined in several studies. Using regression models, these factors could predict, at best, only $26 \%$ of the variability in oesophageal acid exposure. ${ }^{910}$

One hypothesis proposed by several of the above investigators is that psychological factors sensitise the individual to perceive heartburn at lower hydrogen ion concentrations or with shorter episodes of oesophageal acid exposure. ${ }^{810}$ Such a relationship was suggested as long ago as 1935 by Asher Winkelstein, who first linked oesophagitis with the reflux of hydrochloric acid. ${ }^{11}$

When patients with heartburn are questioned, $60 \%$ recognise stress as a causative factor. ${ }^{12}$ Bradley et al, who examined this increased incidence of heartburn during stress, found that GORD patients with high levels of 'gastrointestinal susceptibility' (a scale on the Millon behavioral health inventory) did report more episodes of heartburn but that these were not associated with an actual increase in oesophageal acid exposure. ${ }^{13}$ When the same group applied relaxation techniques to their patients, however, not only was there a reduction in reports of heartburn but the total duration of oesophageal acid exposure also fell. ${ }^{14}$

Compared with healthy controls, GORD patients display higher anxiety, obsessionality, pessimism, and gastrointestinal susceptibility. ${ }^{1516}$ Comparison with disease controls confirms the increased levels of anxiety and also notes increased depression. ${ }^{17}$ In addition to these psychological traits, GORD patients also have an increased likelihood of previous psychiatric diagnoses. ${ }^{16}$

There is some evidence to suggest that GORD patients are a heterogeneous group. When they are divided into those with (a) oesophagitis, (b) normal endoscopy but abnormal $\mathrm{pH}$ monitoring, (c) normal endoscopy and $\mathrm{pH}$ monitoring, and (d) other pathology on endoscopy, these groups show differences both in psychological profile and in their ability to discriminate episodes of reflux from nonreflux periods. ${ }^{14} 15$

The individual's attitude to daily occurrences, whether minor irritants such as filling in forms or major life events, is another psychological aspect which has been examined. Patients with GORD are more likely to interpret these events as 'hassles' or to perceive them with greater intensity. ${ }^{1517}$ It is the patients who score highly for anxiety or who have poor social support that have the highest 'hassle factor'. ${ }^{18}$ The importance of poor social support in GORD has been further highlighted by a study which showed that GORD patients receive more behaviour reinforcing support from their spouses than patients with irritable bowel syndrome. ${ }^{16}$

Their perception of internal physiology, namely acid reflux, has also been examined. Those patients with a poor 
correlation between symptoms and acid reflux on $\mathrm{pH}$ monitoring had higher levels of anxiety and hysteria. They also tended to have less adequate social support. ${ }^{19}$ This finding has also been described in patients with noncardiac chest pain: those with abnormal psychological profiles and inadequate social support show poorer correlation between chest pain and acid reflux. ${ }^{20}$

These findings suggest that the symptoms could be caused by stimuli other than the acid reflux and are at variance with other studies which indicate that patients with high levels of anxiety are more, not less, sensitive to changes in their body's physiology. ${ }^{2122}$ For example, patients with chest pain but normal coronary arteries are more aware of the angiogram catheter within the heart than patients with coronary artery disease. ${ }^{23}$ An alternative explanation which is consistent with previous research, would be that patients with high levels of anxiety or poor social support, or both, are more sensitive to acid reflux. As such they may be aware of $\mathrm{pH}$ drops from 6 to 4.5 or of very brief drops below pH 4, neither of which register as acid reflux events. This is also in accord with the previously noted differences in individual acid sensitivity. ${ }^{8}$

In attempting to explain the relationship between psychological factors and GORD, at least three possible mechanisms can be advanced. Firstly, there may be a factor associated with the psychological differences which influences acid reflux. For example, increased alcohol consumption and smoking at times of stress may affect oesophageal function and mucosal protection. There is also a resurgence of interest in the role of aerophagia which increases with emotional distress and produces gastrointestinal symptoms. ${ }^{24} 25$

Secondly, the areas of neuropsychoimmunology and psychoendocrinology are increasingly being explored and it has been suggested that behavioural reactions may activate the immune and endocrine systems. ${ }^{26}$ In a review of the subject, Collins recently furnished evidence for such a role in the irritable bowel syndrome. ${ }^{27}$ This aspect of the brain-gut axis may have a role in linking psychological factors with GORD.

Thirdly, a schematic interpretation, such as the theory of selective perception, may be applied. ${ }^{28}$ Such a model envisages the psychological factors enhancing body awareness, in this case to even physiological levels of acid refluxing into the oesophagus. A vicious circle can then ensue with increasing perception of acid reflux causing increasing patient anxiety about his or her health. This enhanced awareness may also apply to external events with increased 'hassle factor' scores, and may be lessened by the positive, reassuring influence of good social support.

It may be that patients attending hospital are self selected and therefore different from individuals with the disease in the community. It may even be the case that the psychological differences are induced or aggravated by the medical management. These problems are recognised in the irritable bowel syndrome and have some support in GORD. ${ }^{29}$ The management of these patients must therefore include consideration of psychological and social factors. The beneficial effect of relaxation therapy on both symptom reporting and actual acid reflux is encouraging and merits further follow up.

Many areas remain unaddressed. Nothing is known of the neuropsychoimmunology of GORD, if it exists at all. There is no longitudinal study examining the relationship between daily hassles or life events and GORD symptoms. The psychosocial details of GORD patients in the community need further definition and the role of cognitive/behaviour therapy in GORD merits investigation.
In conclusion, despite increased understanding of the pathophysiology of GORD, much of its variability remains unexplained. Recent studies have confirmed psychological and social differences in patients with GORD and these differences correlate with the altered perception of acid reflux. Preliminary data suggest that addressing these issues improves both symptoms and objective acid reflux. There is much scope for further research in this area.

B T JOHNSTON $S$ A LEWIS A H G LOVE

Departments of Medicine and Mental Health,

Queen's University of Belfast,

Royal Victoria Hospital, Belfast B12 6 Bf

Correspondence to: Dr B T Johnston, Department of Medicine.

1 Cairns H. Student's objective. Lancet 1949; ii: 665-6.

2 Osler $\mathrm{W}$. The principles and practice of medicine. New York: Appleton, 1892.

3 Johansson K-E, Ask P, Boeryd B, Fransson S-G, Tibbling L. Oseophagitis, signs of reflux and gastric acid secretion in patients with symptoms of gastro-oesophageal reflux disease. Scand $f$ Gastroenterol 1986; 21: $837-47$.

4 Behar J, Biancani P, Sheahan DG. Evaluation of esophageal tests in the diagnosis of reflux esophagitis. Gastroenterology 1976; 71: 9-15.

5 De Meester TR, Wang CI, Wernly JA, Pellegrini CA, Little AG, Klementschitsch $\mathrm{P}$, et al. Technique, indications and clinical use of 24 hour esophageal pH monitoring. F Thorac Cardiovasc Surg 1980; 79: 656-70.

6 Johnson DA, Winters C, Spurling TJ, Chobanian SJ, Cattau EL. Esophageal acid sensitivity in Barrett's esophagus. $\mathcal{F}$ Clin Gastroenterol 1987; 9: 23-7.

7 Patterson DJ, Graham DY, Smith JL, Schwartz ST, Alpert E, Lanza FL, et al. Natural history of benign esophageal stricture treated by dilatation. Gastroenterology 1983; 85: 346-50.

8 Smith JL, Opekun AR, Larkai E, Graham DY. Sensitivity of the esophageal mucosa to $\mathrm{pH}$ in gastroesophageal reflux disease. Gastroenterology 1989; 96: 683-9.

9 Johnsson F, Joelsson B, Gudmundsson K. Determinants of gastrooesophageal reflux and their inter-relationships. Br $\mathcal{F}$ Surg 1989; 76: $241-4$.

10 Day JP, McDonald JE, Bradley LA, Richter JE. Patients demographics, symptoms and manometric data re poor predictors of gastroesophageal symptoms and manometric data re poor predict
reflux disease. Gastroenterology 1991; 100: A5.

11 Winkelstein A. Peptic esophagitis: A new clinical entity. $\mathcal{J} A M A$ 1935; 104: 906-8.

12 Anonymous. $A$ gallup survey on heartburn across America. Princeton, NJ: The Gallup Organisation Inc, 1988.

13 Bradley LA, Richter JE, Pulliam TJ, Haile S McD, Scarinci IC, Schan CA, et al. The relationship between stress and symptoms of gastroesophagea reflux: the influence of psychological factors. $A m \mathcal{F}$ Gastroenterol $1993 ; 88$ 11-9.

14 McDonald Haile J, Bradley LA, Bailey MA, Schan CA, Richter JE. Relaxation training reduces symptom reports and acid exposure in gastroesophageal reflux disease (GERD) patients. Gastroenterology 1994 107: 61-9.

15 Johnston BT, Lewis SA, Love AHG. Do heartburn sufferers have a specific personality profile? Gastroenterology 1992; 102: A91.

16 Bradley LA, Richter JE, Scarinci IC, Haile JM, Schan CA. Psychosocial and psychophysical assessments of patients with unexplained chest pain. $A m \mathcal{F}$ psychophysical assessments of patient
Med 1992; 92 (suppl 5A): 65-73S.

17 Lieberman D, Baker L, Denberg T. Psychological stress and gastroesophageal reflux disease (GERD). Gastroenterology 1989; 96: A302.

18 Johnston BT, Lewis SA, Love AHG. Anxiety and social support are important factors in gastro-oesophageal reflux disease. Gut 1993; 34 (suppl 1): S17.

19 Johnston BT, Lewis SA, Collins JSA, McFarland RJ, Love AHG. Acid perception in gastro-oesophageal reflux disease is dependent on psychosocia factors. Scand $\mathcal{F}$ Gastroenterol 1995; 30: 1-5.

20 Breumelhof $\mathbf{R}$, Timmer R, Nadorp J, Smout A. Does an abnormal personality profile predict a negative 24-hour esophageal monitoring test in non-cardiac chest pain (NCCP)? Gastroenterology 1992; 102: A431.

21 Barsky AJ. Patients who amplify bodily symptoms. Ann Intern Med 1979; 91: 63-70.

22 Tyrer P, Lee I, Alexander J. Awareness of cardiac function in anxious, phobic and hypochondriacal patients. Psychol Med 1980; 10: 171-4.

23 Frasure-Smith $\mathrm{N}$. Levels of somatic awareness in relation to angiographic findings. F Psychosom Res 1987; 31: 545-54.

24 Cuevas JL, Cook EW, Richter JE, McCutcheon M, Taub E. Emotional distress, relaxation and air swallowing rate: A possible etiologica mechanism in some gastrointestinal disorders. Gastroenterology 1993; 104 A1035.

25 Gierczak S, Chami T, Schuster MM, Whitehead WE. Gastrointestinal symptoms produced by air swallowing. Gastroenterology 1993; 104: A512.

26 Steptoe A. The links between stress and illness. F Psychosom Res 1991; 35: 633-44.

27 Collins SM. Is the irritable gut an inflamed gut? Scand $\mathcal{f}$ Gastroenterol 1992; 27 (suppl 192): 102-5.

28 Kellner $\mathrm{R}$. Hypochondriasis and somatisation. $\mathcal{F A M A}$ 1987; 258: 2718-22.

29 Scarinci IC, Schan CA, Haile JM, Bradley LA, Richter JE. Psychological distress and health care seeking behavior among persons with symptoms distress and health care seeking behavior among persons with symptoms of gast. 